\title{
Romeo y Julieta de Cantinflas: EI humor en la cultura de masas
}

\author{
Romeo and Juliet by Cantinflas: \\ The humor in the mass cuture
}

\author{
Luis Nitrihual Valdebenito \\ Universidad de La Frontera \\ Temuco - Chile \\ anitrihual@ufro.cl \\ Julieta GaLera \\ Asociación Latinoamericana de Científicos Sociales \\ Buenos Aires - Argentina \\ jgalera@sinectis.com.ar
}

Recibido: 29 de marzo de 2011

Aprobado: 24 de mayo de 2011

\section{Resumen}

Este trabajo se enmarca dentro de un proyecto de investigación mayor que los autores se encuentran realizando sobre el cine del cómico mexicano Cantinflas. Este tiene como hipótesis: a) que en un sentido general, el humor de masas constituye un discurso de gran vitalidad cultural que vehicula determinados universos de sentido; b) puntualmente, el cine de Cantinflas -Mario Moreno Reyes- muestra una estrecha relación con su contexto y con la difusión de ideas como la modernización. En este trabajo analizaremos puntualmente la película Romeo y Julieta de Cantinflas En dicha película, esto se revela como la cimentación de universos simbólicos sobre la división de clases en México de principios de siglo XX, mediante la estrategia de la sátira y la parodia.

Palabras Clave: Cine, Humor, Construcción Textual, Generación de sentido, Parodia.

Nitrihual, L.A. y Galera, J. 2011: Romeo y Julieta de Cantinflas: El humor en la cultura de masas.

Arte, Individuo y Sociedad, 23 (2), 97-107

\begin{abstract}
This work is part of a larger research that authors are performing on the cinema of Mexican comedian Cantinflas project. This has as hypotheses: a) constituting a speech of great cultural vitality that conveys specific universes of sense; in a general sense, the humor of masses b) promptly, Cantinflas - Mario Moreno Reyes - cinema displays a close relationship with its context and the dissemination of ideas as modernization. This work will cover timely film Romeo and Juliet by Cantinflas. In this film, this is revealed as the foundation of symbolic about splitting classes in Mexico in early 20th century, through the strategy of satire and parody universes.
\end{abstract}

Key Words: Cinema, Humor, Textual construction, Sense construction, Parody.

Nitrihual, L.A. y Galera, J. 2011: Romeo and Juliet by Cantinflas: The humor in the mass cuture. Arte, Individuo y Sociedad, 23 (2), 97-107

Sumario: 1. El cine del cantinflas. Hacer del cine un objeto de investigación, 2. Humor, quínica e ideología, 3. Romeo y Julieta: clase y regreso al origen, 4. El cine de Cantinflas: el asalto de la burguesía.

5. Conclusiones. Referencias 


\section{El cine de Cantinflas. Hacer del cine un objeto de investigación}

Realizar un trabajo sobre el cine del cómico Cantinflas es una cuestión difícil debido a la cercanía que tenemos con ese objeto de disfrute. Es como acercarse a la persona amada y descubrir errores que la hacen humana y que la transforman de inmediato en objeto de miradas, ya sean fijas o de reojo, que le buscan el defecto, el problema, la contradicción.

Como ya señalamos en un trabajo anterior (Galera y Nitrihual, 2009) donde tuvimos oportunidad de trabajar sobre la película Un día con el Diablo, el cine de Mario Moreno Reyes "Cantinflas" muestra una clara relación con su contexto socio histórico: específicamente con la difusión de conceptos fetiche norteamericanos como la "libertad", "democracia" y también describe la posición aliada de México (el discurso político) durante la Segunda Guerra Mundial. Se trata, sin más, del uso del cine como instrumento de propaganda y cimentación de la hegemonía.

No obstante, esta difusión se realiza mediante un discurso que utiliza la sátira, la risa, la parodia, como instrumento de comunicación y difusión.

En síntesis, se trata de señalar que las películas de Cantinflas adquieren, como cualquier objeto al interior de las industrias culturales, la forma mercancía que se entenderá como la base de la acumulación capitalista, como la objetivación de la riqueza. Como señala Marx (1975, p. 43), las "sociedades en las que domina el modo de producción capitalista se presenta como un enorme "cúmulo de mercancías" y la mercancía individual como la forma elemental de esa riqueza (...)" En primer lugar, Marx señala que la mercancía es una cosa exterior que satisface necesidades y posteriormente distingue su realidad bifásica constituida por un valor de uso y un valor de cambio.

Particularmente en el caso de los medios de comunicación, y el cine en este caso, estos convierten la información en mercancías y como ha señalado Boladeras (2001, p. 59) la función social de la comunicación se transforma en instrumento de creación de riqueza e influencia política.

Pero esta forma mercancía no es unitaria, es más bien contradictoria y revela como el proceso de producción de públicos que consuman esas películas, tiene una determinación de clase y unas vías de fuga por las cuales se asoman los compadritos, los rotos, los peladitos, que enuncian en su habla, las carencias de los relegados que se las arreglan para subsistir.

Justamente en el sentido de la contradicción de algunas películas de Hollywood que se muestran aparentemente críticas, en un conciso trabajo de Slavoj Zizek (2008) titulado Arte y Capitalismo se muestra como el cine de Hollywood y por extensión, el cine que sigue este modelo, presentan en muchos casos una suerte de marxismo empobrecido en donde el orden de clases casi siempre se mantiene inalterable. En el caso del cine del cómico mexicano, se revela como la enunciación de una clase social que nunca llega a escalar socialmente que nunca llega a escalar manteniéndose siempre en SU lugar.

Siguiendo esta ruta crítica que considera al cine de Cantinflas un microcosmos de la sociedad mexicana, este trabajo se enmarca dentro de un proyecto mayor que los autores se encuentran realizando sobre el cine del cómico mexicano realizado durante la denominada Época de oro del cine mexicano (1939-1945) (Viña, 1987, p. 
104) y que revela la relación que dichas películas guardan con su contexto económico político.

Particularmente, en la película Romeo y Julieta esto se revela como la cimentación de universos simbólicos vinculados a la división de clases y al rol de los sujetos sociales en la sociedad capitalista de principios del siglo XX.

\section{Humor, quínica e ideología}

En el artículo El acto de creación, Arthur Koestler (2002, p. 191), señala que el humor habría que enmarcarlo dentro de una actividad creativa que tiene entre sus principales características: sonrisa cómica, agudeza, sátira, personificación, caricatura, juego de palabras, adivinanza, desenmascaramiento, coincidencia. Diferente al acto artístico, que por ejemplo utiliza la alegoría como forma narrativa principal, el humor hace uso de la sátira, caso que se encuentra claramente presente en obras como las de los Hermanos Marx, en Chaplin y en Cantinflas.

En esta medida, el discurso humorístico juega con la sátira como forma de burla ante el discurso del otro. En este sentido, el discurso humorístico es una de las más antiguas formas de comunicación y dado que el burlado siempre es el otro, aunque sea un discurso que refiera a la mexicanidad, etc. desde dentro, el enunciador siempre tiene la distancia crítica y la impunidad de quien dice sin querer decir, de quien sólo hace reír. De este modo, la risa, como ya lo había advertido la filosofía es un acto impropio que siempre esconde algo. En específico, como también lo habían destacado los filósofos cínicos, la risa es un acto crítico, puesto que siempre reír, es reírse de...

En esta medida, el discurso humorístico aparece ante nuestros ojos como un conjunto más o menos elaborado de comunicaciones mediatizadas y en esa medida debe establecerse su correlación con el medio en el que se difunde (el cine en este caso particular). Medio que por su parte forma parte de una industria cultural que contribuye a legitimar determinadas hegemonías.

En la filosofía de Peter Sloterdijk, particularmente en su libro Crítica de la Razón Cínica (2007,) se exponen los conceptos de cinismo y quinismo, como dos formas de funcionamiento ante la ideología. Para el autor alemán, el cinismo se manifiesta como una falsa conciencia ilustrada, esto pues el cínico moderno es alguien que sabe de la inutilidad incluso de la crítica, pero aún así continúa como si no pasará nada. Desde este punto de vista, el moderno cínico se manifiesta en el humor necesariamente de masas, esto pues el bufo de masas aunque pueda criticar no rompe su propia condición de mercancía, su mecánica de dichos y verborrea que reafirma la continuidad del poder de los que controlan la producción de sus discursos.

Cabe preguntarse qué papel desempeña el humor de masas en la construcción de hegemonías. Por otro lado, vale la pena continuar pensando en el papel cínico de los medios de comunicación que persisten en generar sus propias hegemonías que posibilitan su funcionamiento y su papel como garante del "buen orden burgués".

En contraposición en cínico moderno, Sloterdijk (2007) propone al quínico; este representa el "rechazo popular, plebeyo, de la cultura oficial por medio de la ironía (...) el procedimiento clásico kínico es enfrentar las patéticas frases de la ideología dominante -su tono solemne, grave- con la trivialidad cotidiana"(Zizek, 2003, p.57) 
Ahora bien, la complejidad de esta distinción sloterjdiana es que este gesto quínico se manifiesta muchas veces en las mismas industrias culturales que generan los espacios para que esta burla se manifieste.

El gesto quínico es popular y por medio de él, nos señala Sloterdijk (2007), se enfrenta, mediante la burla o la parodia (como en el caso de la película Romeo y Julieta de Cantinflas) a la seriedad oficial. Ahora bien, en el caso que nos interesa, el cine de Cantinflas conserva algunas características quínicas, por ejemplo en el monólogo del comienzo de la película Romeo y Julieta en que Cantinflas se queja, en el habla de los "peladitos", del alza de todos los productos:

\begin{abstract}
"ya ve usted como está todo de caro señor comisario, la gasolina no se consigue o se consigue, pero muy alterada señor, luego que agarra usted, el hule, las llantas, que me dice usted de las llantas, señor, que les ha dado de vender hule sintético, sintético sin hule (...) se ponchan luego luego (...) la banda del ventilado, la banda rateros que tienen monopolizado todo y luego el arroz a 12 el kilo..."
\end{abstract}

Como puede leerse, es una crítica social importante, pero nuestra hipótesis indica que la cinematografía de Cantinflas se mueve en una línea delgada con el cinismo moderno. El procedimiento clásico de Cantinflas es la burla lingüística (el cantinfleo), pero en un nivel paradigmático mayor, el personaje siempre retorna a sus orígenes humildes, validando las instituciones del poder, participando de ellas, en un retorno trágico del cínico moderno ${ }^{1}$.

La respuesta cínica del cine de Cantinflas deja en jaque a una crítica de la ideología. Las burlas y la parodia de esta mercancía de la industria cultural nos dice que hagamos lo que hagamos continuaremos en nuestra misma posición. La risa es entonces una tragedia y la burla un mecanismo catártico de la sociedad capitalista, apenas un lujo que podemos permitirnos.

En esta medida, la sátira de Cantinflas regresa sobre sí para reforzar el status quo. No es una sátira que vaya contra el poder, sino que se articula con él para hacer más llevadero el "sufrimiento" de las clases bajas mexicanas.

¿Pero en qué medida el cine de Cantinflas constituye un triunfo de la ideología de la clase dominante? Primero, no necesaria ni fundamental en el contenido de la película sino más bien en el procedimiento en que la realidad "se apodera de nosotros realmente sólo cuando no sentimos ninguna oposición entre ella y la realidad - a saber, cuando la ideología consigue determinar el modo de nuestra experiencia cotidiana de la realidad" (Zizek, 2003:80).

Por ello, no nos extraña ni preocupa que en las películas de Cantinflas, en su larga filmografía, haya pocos cruces de clases. Es decir: Cantinflas suele enamorarse de la niña rica, pero esta nunca le corresponde, o si lo hace, terminan separándose por algún motivo.

\title{
3. Romeo y Julieta: clase y regreso al origen
}

Es necesario avanzar en un análisis del cine como texto que recupere un horizonte material e histórico donde los procesos de generación de sentido son determinados, controlados y seleccionados, retomando la paranoica sentencia de Foucault (1993). 
El texto, entendido así, constituye una construcción intersubjetiva de interacambio social (Lozano, Peñamarín y Abril, 2004) donde la ideología funciona más bien como articuladora de la realidad.

Pero vamos a la película que nos interesa analizar en este trabajo. Romeo y Julieta narra las peripecias de un taxista que debe hacerse pasar por un renombrado, experimentado y con un elevadísimo nivel cultural y social -propios de la clase alta-, actor de teatro en la casa de una familia millonaria con el fin que el pretendiente de la hija de dicha familia -de clase acomodada- pueda quedar bien ponderado en comparación con el actor al demostrarse que este último (Cantinflas) es un "impresentable" y que la familia -aunque él pretendiente no es de clase alta- lo valore y lo acepte como esposo de su hija. En el fondo se trata de la reescritura del tópico shakesperiano de amor imposible entre familias que se odian.

Evidentemente, la primera cuestión que salta a la vista en esta película es su relación intertextual con la obra de William Shakespeare, Romeo y Julieta. La obra de Shakespeare es tomada como base - por el director Miguel Delgado- para realizar el guión de la película, pero contextualizándola en el México de años 40 y elevando al "pelado" a la categoría de símbolo del carácter mexicano popular (Bragança, [2003]: 53). Lleva razón Monsivais cuando asegura que la irrupción del "pelado" en el lenguaje permite su visualización como sujetos sociales ya que antes se encontraban expulsados de la construcción de la nación. Sin embargo, el análisis de Monsivais se queda corto pues para la construcción de la hegemonía, el proletariado también debe ser incorporado para transformar lo popular en arte y cultura.

De acuerdo a lo que plantea Néstor García Canclini en su obra "Ideología, cultura y poder" (1999) citando a Pierre Bordieu, el sistema de relaciones constituido por todos los agentes sociales vinculados al proceso de producción y comunicación de una obra (artistas, productores, guionistas, distribuidores, etc.), van a configurar un modo de organizar el modo de hacer y comunicar el mensaje.

Romeo y Julieta fue producida y guionada por Miguel Delgado -quién se formó durante 4 años en Hollywood-; además fue producida por la productora de Mario Moreno, POSA FILMS; realizada en los estudios del Estado C.L.A.S.A Films; y distribuida por Mexican Film Trust, una empresa productora y distribuidora de capitales estadounidenses que apoyó el film ¡Viva México! de Sergei Eiseinstein, pero con la condición de que esta fuera una película "apolítica" y que antes de la post producción fuera sometida a la censura estatal para respetar el discurso oficial.

Una primera cuestión que salta a la vista es la dificultad para discernir hasta qué punto el texto de Romeo y Julieta está producido con la intención de instaurar y mantener el orden establecido, o como está implícito en la lógica de la parodia: expresa la indignación hacia alguien o algo e intenta instaurar una crítica al orden establecido.

La cuestión central en este trabajo es que debe considerarse contradictoria cualquier manifestación de las industrias culturales debido al carácter mercantil en que devienen sus producciones y que en última instancia comprueba la eficacia del sistema de convertir en mercancía todo lo que toca. No se trata fundamentalmente, en este caso, de repetir hasta qué punto la película se encuentra reproduciendo las ideologías de la clase dominante (lo que incluso puede resultar evidente), sino más 
bien establecer el procedimiento cínico mediante el cuál el discurso satírico se repliega sobre sí para dar cuenta, antes que de la crítica la ideología, del refuerzo de la misma. En la película de Cantinflas Romeo y Julieta, los vicios individuales o colectivos, las locuras, los abusos o las deficiencias se ponen de manifiesto por medio de la ridiculización, la farsa, la ironía y finalmente la parodia de la obra de Shakespeare.

El procedimiento de la sátira permite en este sentido, reírse tanto del otro, víctima de la burla, como reconocerse a sí mismo. Por ello, el humor de la cultura de masas es un humor propio de cinismo. Este humor, convertido ahora en mercancía de gran valor en las industrias culturales, no hace otra cosa que revelar, en un sentido profundo, la inutilidad del gesto crítico.

En la película Romeo y Julieta de Cantinflas, todos estos recursos son utilizados para realizar una parodia mexicana de la obra de Shakespeare. Se trata, en este sentido, de una obra muy interesante para ser representada en México por tres motivos:

1) La sátira coloca en contacto dos espacios conflictivos de América. A saber: la alta cultura europea, representada por la obra de Shakespeare, y la burla popular ante la seriedad de dicha alta cultura. Pero nuevamente, al igual que en la película Los Tres Mosqueteros, la parodia termina rindiendo homenaje a la obra. La representación de Cantinflas es la concreción de los deseos criollizados de incorporación del discurso y tradición ilustrada.

2) En México a principios del siglo XX los valores políticos, sociales y culturales de la burguesía europea estaban arraigados en la clase alta y en la ascendente clase media debido a la huella histórica, económica, política, social y cultural que dejó el Imperio francés de Maximiliano I en el siglo XIX. El gusto por lo europeo -como es representado en la película Romeo y Julieta- es parte de la identidad de clase de la burguesía mexicana. Pero lo curioso, es que también constituye cierto rasgo de la identidad de la cultura de la clase media en ascenso que quiere "parecerse" a la élite hegemónica.

Se trata de la búsqueda de instalación de los valores idealizados de la cultura europea. Estos, burlados, cambiados, cantinfleados, se materializan en la genial representación teatral de Cantinflas. De este modo, la simple burla no sirve pues la narrativa reproduce la lógica de clases que señala que el héroe (Cantinflas) debe regresar a su vida de "peladito".

La subversión de estas clases bajas es lógicamente contenida en los márgenes de la propuesta hollywoodiense. Se trata, como ya lo hemos señalado desde Zizek (2003) de un marxismo empobrecido en que las clases bajas aparecen en la pantalla con sus sufrimientos y dolores, pero que luego de un breve paseo por el "paraíso" regresan a sus casas herrumbrosas.

En Romeo y Julieta esto se logra con la concreción del anhelo de Cantinflas: tener un automóvil nuevo para su trabajo de taxista. Tengamos en cuenta que toda la trama de la película se articula sobre la aspiración de Cantinflas de tener un automóvil nuevo donde pasear a su novia y trabajar como taxista.

3) En México, las prácticas de casamiento intra clasista era visto como natural y la inter clasista era vista como antinatural, como sucede en la obra de Shakespeare, de modo que pareciera un tema interesante y cercano para ser representado en la parodia. 


\section{El cine de Cantinflas: el asalto de la burguesía}

En este apartado nos interesa establecer la relación entre texto y contexto: entre el film Romeo y Julieta de Cantinflas y la realidad histórica, económica, política, social y cultural que vivía México en la década de los 40, representadas en las películas de Mario Moreno Reyes pertenecientes a la Época de oro del cine mexicano (19391945).

A diferencia de las películas del Indio Fernández que fueron y son muy analizadas por especialistas en cine como Ricardo Pérez Monfort o Carlos Monsivais, las películas de Cantinflas no han sido analizadas en profundidad salvo por el estadounidense Jeffrey M. Pilcher en su obra Cantinflas and the chaos of mexican modernity.

Se hace referencia a Mario Moreno Reyes -Cantinflas- como uno de los pilares de la época de oro del cine mexicano, junto al Indio Fernández, pero a diferencia de este último, que representa la vida rural, Cantinflas escenifica la vida del México urbano. La filmografía del mexicano muestra al migrante del campo, el famoso peladito como es retratada toda una masa social de inmigrantes de principios de siglo XX que llegan a la gran ciudad en busca de mejores condiciones de vida- (Iturriaga, 1951).

Como ya hemos señalado, la película Romeo y Julieta, antes que un discurso crítico de la sociedad imperante en ese momento, es un espacio de afianzamiento del status quo. Con ello, contribuye a legitimar la estructura de clases vigente y a instaurar un nuevo modelo de sociedad -caracterizado por la consolidación del Estado-Nación, la modernización e industrialización de la economía, y la urbanización y masificación del consumo-, a través de las estructuras simbólicas o estructuras ideológicas-culturales que permiten "educar" a las clases medias y bajas masivamente, a través de un nuevo medio de comunicación, información y difusión masivo, como el cine. Este, por tanto, constituye un vehículo mediador entre el discurso dominante y la praxis de las clases bajas.

La finalidad del uso de este medio educativo es legitimar el orden imperante y modificar el habitus de clase de las clases dominadas, que constituye la estructura de clases que organiza el modo en que estas actúan y que puede ser modificado levemente a través de la educación y de la adaptación del individuo a la sociedad (García Canclini, 1999, p. 40).

En su obra "La estructura social y cultual de México", José Iturriaga señala que en México de principios de siglo existía una capilaridad social: es decir una igualdad política y una desigualdad económica que permitía que los ciudadanos de distintas clases sociales tuvieran los mismos derechos políticos aunque no tuvieran las mismas posibilidades económicas. Esto permitía que en las clases más bajas existieran el impulso o la necesidad de ascenso social (Iturriaga, 1951, p. 25).

Esto se puede ver en el film Romeo y Julieta en la relación que mantiene Cantinflas con su novia. En las primeras escenas de la película, ésta lo abandona en medio de la calle porque su auto está destartalado y ella está cansada de tener que pasar penurias y peripecias a causa del estado del automóvil, lo cuál también es sentido por el "peladito" angustiado, a quién esa misma noche se le presenta una oportunidad, un negocio que le permitiría ganar el dinero necesario para cambiar su taxi por uno más moderno y así complacerse y complacer los deseos de su novia y poder ascender en la escala 
social, aunque sea de modo aparente a través del acceso al consumo. En suma, todas las aventuras del héroe en la película pueden ser reducidas a esta búsqueda inicial de ascenso social.

En su obra, José Iturriaga señala que hay varios motivos por los que se componen las clases. Entre ellos se destacan la composición por motivos económicos; la composición por motivos culturales; y por hábitos de conducta (Iturriaga, 1951, p. 24). En este sentido, podemos observar en Romeo y Julieta que cada clase está tiene características culturales (educación, modales y gusto estético), características económicas (vestimenta, bienes materiales, hábitos de consumo y dinero) y hábitos de conducta (estilo de trabajo, lenguaje, gesticulación, forma de expresión, etc.) que son propios de cada clase y están extremadamente estereotipados como para establecer un orden y no prestarse a equívocos. Para que cada sujeto se identifique con el lugar que ocupa y debe ocupar en la sociedad, para que esta esté normalizada y funcione correctamente.

El investigador mexicano también plantea que existen deseos de ascenso social y cultura en la clase baja y que las condiciones políticas y económicas de México durante los gobiernos de la década de los 30 y 40 lo posibilitaban, en cierta medida, aunque estos no se dan de la manera que la clase baja hubiera querido. Esto se ve plasmado en la película Romeo y Julieta de Cantinflas, como lo hemos señalado con anterioridad, en el deseo de comprar un bien material, un taxi nuevo, no sólo con la finalidad de poder trabajar mejor sino de poder acceder al disfrute, al goce del tiempo libre, como lo hace la clase media y la clase alta, sobre todo.

Por otro lado, la búsqueda de ascenso social puede verse plasmada en el pasaje de la película en el que la novia de Cantinflas va al teatro a ver la obra Romeo y Julieta de Shakeaspeare publicitada por la participación del actor extranjero, renombradísimo y reconocidísimo por la Academia Sheskpeareana por sus representaciones de la obra de este actor en Europa, por el que se estaba haciendo pasar el "peladito" como estrategia para ganar dinero para su fin: comprarse el taxi nuevo donde pasear a su "changuita".

En ese sentido, cabe destacar que a principios de siglo, el cine era un medio de masas pero el teatro -salvo el teatro criollo, de características más circenses- era vedado a la élite. Y el hecho de que en esta obra, representada en la película de Cantinflas, participara un eximio actor extranjero sheaspereano era aún más un factor elitista, que hacía que el teatro fuera accesible para unos pocos elegidos, pero que en el film se demuestra que es accesible aún para la clase baja por la asistencia a la sala de la novia del "peladito", quién a decir verdad, se mostraba como una persona que no entendía del todo los códigos teatrales.

En relación a la representación de la obra Romeo y Julieta de Sheakespeare en la película Romeo y Julieta de Cantinflas, se puede decir que esto no es casual y tiene que ver con el valor cultural y estético que se le daba en la época a lo europeo. Y aunque la parodia constituye un recurso retórico que permite establecer una separación entre el texto parodiado (la obra de Sheakespeare) y el texto parodiante (Romeo y Julieta de Cantinflas), la sola representación supone un modo de dependencia ${ }^{2}$.

Por la influencia contemporánea actual, específicamente en las clases medias mexicanas de la cultura francesa o europea, como legado del Imperio de MaximilianoI, 
podríamos inferir que el cine, específicamente las películas de Cantinflas, han ayudado a instaurar o mantener esos valores y gustos estéticos, culturales y sociales.

Iturriaga también explica que en la década de los 40, el crecimiento de las ciudades multiplicó notablemente el sector no asalariado: artesanos pobres, comerciantes pequeños o puesteros, vendedores y trabajadores ambulantes, etc., es decir muchas formas de trabajo que constituyen subempleo que son poco remunerativas (Iturriaga, 1951: 40-41). Esto se puede ver en todas las películas de Cantinflas donde el peladito desempeña siempre alguno de esos tipos de empleos. En el caso de Romeo y Julieta, representa a un taxista.

En el film Romeo y Julieta se muestra claramente una división de clases: la clase baja, representada por Cantinflas y su novia -incultos, brutos, y en el caso de Cantinflas con empleo no calificado, con deseos de ascenso social porque quiere comprar un automóvil moderno para ascender; la clase media acomodada representada por el novio de Julieta -que no puede casarse con ella porque su padre le niega su mano porque este no tiene un nivel cultural alto (es más alto que el de Cantinflas, su trabajo no es corporal, su gusto cultural es más elevado que el del "peladito" pero no tan refinado como el de la clase alta); y la clase alta representada por Julieta y su familia, pero sobre todo por su padre, que representa lo más alto de la cultura, la riqueza, el poder.

Una cuestión igualmente interesante en las películas de Cantinflas, y, por supuesto, también en Romeo y Julieta, es la representación de los funcionarios públicos. Estos, si bien representan a la autoridad, son burlados y ninguneados constantemente. Cabe reflexionar en el imaginario que se construye de la autoridad política-policial, ya que muestra como la creciente masa burocrática es representada como los "idiotas" que no saben qué pasa en "el pueblo". Es como si toda la ira de las masas, toda la fuerza de la burla hacia la autoridad, tuviera la finalidad (anulada) de subvertir el orden; pero que es finalmente castrada por el conformismo de las clases proletarias que se manifiesta en las películas de Cantinflas.

Esta presencia importante de los funcionarios burocráticos se debe a que durante la década de los 30 y 40 con las presidencias de Lázaro Cárdenas y de Manuel Ávila Camacho, México se modernizó notablemente, se impulsó la modernización de la estructura del Estado y el aumento de funcionarios públicos para el desarrollo y la ampliación del aparato gubernamental de México. Esto le dio gran importancia a este sector de la población. Esto se percibe claramente en las películas de Cantinflas del periodo $1930-1945^{3}$.

Finalmente, en la década de los 40 el desarrollo industrial en México tiene una resonancia inevitable en la estructura de la sociedad en su conjunto, y se va gestando un cambio en la composición y en la relación de las clases. Esto también se puede apreciar en la película Romeo y Julieta en la que triunfa el amor y la movilidad social, porque finalmente Julieta logra quedarse con su amado y Cantinflas, puede intuirse, consigue comprar su automóvil, lo cual permite su felicidad total.

Luego de este breve análisis de la película Romeo y Julieta, y el análisis de la estructura de clases y el contexto económico, político, social y cultural de los años 40 , podemos asegurar que el texto tiene estrecha relación con el contexto de su época. Esto no es un hecho fortuito si no un hecho planificado por la élite hegemónica, 
como dijimos, para mantener el orden vigente e instalar nuevos valores relacionados con la modernidad y la modernización de la sociedad mexicana de la primera mitad del siglo XX.

\section{Conclusiones}

En este trabajo nos planteamos como punto de partida averiguar: a) si el humor constituye un discurso cultural que vehicula valores ideológicos y universos simbólicos; y b) si la película Romeo y Julieta de Cantinflas muestran una relación con su contexto social, cultural y político.

En conclusión, estamos en condiciones de aseverar que ambas premisas se cumplen.

Nuestra hipótesis indica que la cinematografía de Cantinflas se mueve en una línea delgada con el cinismo moderno. El procedimiento clásico de Cantinflas es la burla lingüística (el cantinfleo), pero en un nivel paradigmático mayor, el personaje siempre retorna a sus orígenes humildes, validando las instituciones del poder, participando de ellas, en un retorno trágico del cínico moderno.

En ese sentido, el humor es utilizado como modo de discurso, no para burlar el orden imperante si no para mantener el status quo y hacer más llevadero el dolor de las clases bajas. Pareciera que reírse, en el humor de masas, constituye también una forma de conformismo cínico.

En este sentido, de acuerdo a los tiempos que corrían en la década de los 40 , el cine y el discurso humorístico fueron mediaciones necesarias para que le modelo político, económico, social y cultural que deseaba sostener y también modificar en algunos aspectos el poder hegemónico y modernizar a la sociedad para instaurar valores como el consumismo, gustos estéticos, formas de comportamiento, etc.

\section{Referencias}

Agamben, G. (2003). Profanaciones. Barcelona: Anagrama.

Boladeras, M. (2001). La opinión pública en Habermas. Revista Anàlisi 26, pp. 5170.

Braganca, M. (2003). Cantinflas, um peladito no proyeto de modernizaçao do Estado Mexicano. Revista Eletrônica da ANPHLAC - número 6 (38) Recuperada de www.anphlac.org/periodicos/ revista/revista6/cantinflas.pdf

Foucault, M. (1993). Las palabras y las cosas. Barcelona: Siglo XXI.

Galera, J. y Nitrihual, L. (2009). Cantinflas entre risas y sombras. Un análisis semiótico cínico. Revista Anagramas, Vol. 8, n 15, pp. 99-115.

García Canclini, N. (1999). Ideología, cultura y poder. Buenos Aires: Oficina de Publicaciones del Ciclo Básico Común de la Universidad de Buenos Aires.

Iturriaga, J. (1951). La estructura social y cultural de México. México: Fondo de Cultura Económica.

Koestler, A. (2002). El acto de creación: el bufón. Cuadernos de Información y Comunicación, CIC, Vol. 7. 2002. pp.189-120. 
Lozano, J.; Peñamarín, M. y Abril, G. (2004). Análisis del discurso. Hacia una semiótica de la interacción textual. España: Cátedra.

Marx, K. (1975). El capital. Tomo I/ Volumen I. El proceso de producción del capital. Argentina: Siglo XXI.

Peñamarín, C. (2002). El humor gráfico del franquismo y la formación de un territorio translocal de identidad democrática. Cuadernos de Información y Comunicación, CIC Vol. 7, 2002, pp. 335-380.

Sloterdijk, P. (2007). Crítica de la razón cínica. España: Siruela.

Viñas, M. (1987). La llamada época de oro (1941-1945) y el crecimiento espectacular (1946-1950) en Viñas, M. Historia del Cine mexicano (100-168) México: UNAM.

Zizek, Slavoj; Alemán, Jorge y Rendueles, César. (2008). Arte, ideología y capitalismo. Madrid: Ediciones Pensamiento.

Zizek, S. (2003). El sublime objeto de la ideología. Argentina: Siglo Veintiuno.

\section{Notas}

1. Ahora bien, cabe discutir, en este punto, lo señalado por Zizek (2003) en torno al estadio postideólogico al que nos conduce la constatación del funcionamiento moderno cínico, pues pareciera que a los sujetos postmodernos la ideología ya no le interesa y van por la vida sólo buscando placer. Esto no será tan así, desde el punto de vista de Zizek, pues pareciera que la ideología se ha disfrazado de apolítica.

2. La cuestión central en este punto, es pensar el papel de la Parodia en la filmografía del mexicano, como ha señalado Agamben, hablando de la seriedad de la Parodia (2005: 52) "Sin embargo, el parodiante puede albergar razones serias para renunciar a una representación directa de su objeto".

3. Ejemplos de este fenómeno se encuentran las películas de Cantinflas: Ahí está el detalle (1940), Ni sangre, ni arena (1941), El gendarme desconocido (1941), Los tres mosqueteros (1942), Gran Hotel (1944), Un día con el diablo (1945). 